\title{
RENDA FAMILIAR E MERCADO DE TRABALHO um balanço da década
}

\author{
Nádia Pinheiro Dini \\ Estatística, Gerente de Métodos Quantitativos da Fundação Seade \\ Paulo de Martino Jannuzzi \\ Analista da Fundação Seade, Professor da PUC-Campinas \\ Maria Paula Ferreira \\ Estatística, Analista da Fundação Seade \\ Neuci Arizono \\ Estatística, Analista da Fundação Seade
}

$\mathrm{A}$ persistência e a gravidade dos problemas sociais vivenciados na sociedade brasileira e a exigüidade dos recursos públicos disponíveis para encaminhar soluções definitivas para os mesmos têm ensejado um esforço crescente das agências e institutos ligados às atividades de planejamento público na definição de instrumentos tecnicamente mais precisos para diagnósticos da realidade social, com a finalidade de subsidiar de forma mais competente o poder público na formulação de políticas e no acompanhamento de seus programas sociais.

Desde meados dos anos 80, têm ganhado relevância os estudos e instrumentos de pesquisa voltados ao levantamento das condições de vida, da situação de pobreza e indigência da população, da cobertura e efetividade das políticas públicas. Embora estas temáticas já estivessem sendo tratadas nas universidades e figurassem como objeto de investigação estatística e análise nos órgãos ligados ao planejamento público desde final dos anos 60 , seria a partir da crise e da estagnação econômica na década passada - e seus efeitos sobre o empobrecimento de diversos segmentos sociais - que estas questões passariam a comparecer com maior freqüência e profundidade na literatura acadêmica e na agenda política, passando a disputar a centralidade do debate social com os estudos sobre distribuição de renda e sobre a constituição do mercado de trabalho urbano - temáticas privilegiadas no contexto do aumento generalizado e desigual da renda e do crescimento acelerado da população urbana nos anos 70 (Magalhães, 1993; Nepp, 1994; PNUD, 1991). ${ }^{1}$

Na presente década, a preocupação com estas temáticas sociais revela-se, no âmbito das agências vinculadas ao planejamento em nível federal, pela reformulação dos questionários e ampliação temática das PNADs, por parte do IBGE, pelos levantamentos sobre a situação educacional, realizados no Inep, pelos esforços de disseminação do uso dos registros administrativos do Ministério do Trabalho (Rais e Caged) e pelas análises sobre nível e distribuição de renda, pobreza e gasto social, no Ipea. ${ }^{2}$

No âmbito da Fundação Seade, a preocupação com a questão da pobreza e a avaliação da efetividade social das políticas públicas vêm se revelando, nos anos 90, por uma série de iniciativas, sendo a mais importante a realização da Pesquisa de Condições de Vida (PCV) em 1990, bem como os esforços para seu aprimoramento metodológico e ampliação do escopo investigativo e da abrangência espacial da pesquisa nas suas edições posteriores (1994 e 1998). Ressaltam-se também as análises de mercado de trabalho com base na Pesquisa de Emprego e Desemprego (PED), nos últimos quatro anos, e a elaboração de pesquisas específicas na área de habitação popular. ${ }^{3}$

Mais recentemente, com o objetivo de atender a essa demanda crescente por informações estatísticas voltadas à formulação de políticas sociais e potencializar o uso de suas fontes de informação, desenvolveu-se na Fundação Seade, entre 1997 e 1998, a primeira etapa do projeto "Acompanhamento Conjuntural da Renda e Pobreza na Região Metropolitana de São Paulo", valendo-se da experiência e estudos anteriores desenvolvidos na instituição e por Árias (1996 e 1998) sobre o tema. O objetivo do projeto era desenvolver e testar uma metodologia que permitisse o acompanhamento sistemático do nível e da distribuição da renda familiar per capita na Região Me- 
tropolitana de São Paulo (RMSP) segundo diferentes recortes sociodemográficos, com base nos dados levantados periodicamente pela Pesquisa de Emprego e Desemprego.

Procurando sistematizar parcela das atividades desenvolvidas no referido projeto, esse texto apresenta uma análise da evolução da renda familiar e sua distribuição na RMSP na presente década, no contexto das diferentes conjunturas econômicas vivenciadas e no bojo das transformações estruturais da base produtiva nacional e paulistana. Este estudo foi conduzido com base na série histórica da PED de 1990 a 1998, seguindo a metodologia proposta por Árias (1996) de acompanhamento da massa de renda familiar per capita e de análise de seus fatores determinantes.

Vale esclarecer, de início, que a renda familiar aqui analisada corresponde àquela passível de ser computada através da PED no período. Embora a pesquisa não levantasse, no período em questão, informações mais abrangentes sobre outras fontes de rendimentos que não as diretamente ligadas ao exercício atual ou passado de um trabalho remunerado, o elevado peso das rendas do trabalho na composição da renda familiar na RMSP pareceu constituir-se em argumento suficientemente forte e consistente para a busca - ainda que parcial - de explicações para o comportamento destas dimensões socioeconômicas - nível e forma de distribuição da renda familiar cruciais ao acompanhamento das condições de vida da população metropolitana. De fato, como mostrou a Pesquisa de Condições de Vida de 1994 na RMSP - com uma captação mais abrangente de fontes de rendimentos -, os rendimentos provenientes do exercício atual ou passado do trabalho (renda do trabalho, aposentadorias, pensões, trabalho ocasional, seguro-desemprego, etc.) correspondem a $97 \%$ da massa total de rendimentos familiares. ${ }^{4}$

Além disso, a possibilidade de estudar o comportamento da renda familiar referida a períodos mais curtos, dentro de cada ano, representava um atrativo de grande interesse analítico em face das oscilações cíclicas e anticíclicas que marcaram o cotidiano da economia brasileira nesta década. ${ }^{5}$ Vale registrar ainda que as tendências aqui apresentadas sobre a evolução da renda familiar são muito próximas daquelas descritas em estudo semelhante elaborado por Árias (1998) para a RMSP de 1990 a 1996, a partir de dados das PNADs - que captam um leque mais extenso de fontes de rendimentos.

Por fim, também é importante observar que a opção pelo estudo da renda per capita - em detrimento de ou- tros indicadores de renda - deve-se à preocupação precípua do projeto em subsidiar a formulação de políticas públicas específicas de combate à indigência e à pobreza. Em que pesem as limitações metodológicas desse indicador, a renda familiar per capita continua sendo a medida mais empregada em estudos nessa temática (Fundação Seade, 1992; Jannuzzi, 1997). ${ }^{6}$

\section{O MODELO DE DECOMPOSIÇÃO DA RENDA FAMILIAR PER CAPITA}

O modelo aqui empregado para análise dos fatores determinantes do nível de renda familiar foi o proposto por Árias (1996; 1998), em que a massa de rendimentos familiares per capita é decomposta, algebricamente, em seis fatores ligados à dinâmica conjuntural do mercado de trabalho ou a tendências socioculturais, socioeconômicas e demográficas de mais longo prazo ${ }^{7}$ (Quadro 1).

$\mathrm{O}$ primeiro fator do modelo tem a finalidade de retratar a contribuição das rendas de outras fontes e membros que não as diretamente geradas pelo trabalho atual dos indivíduos. Na PED, estas rendas adicionais referem-se aos montantes advindos de pensões e aposentadorias da Previdência Social, seguro-desemprego, trabalho ocasional ou excepcional de desempregados, auxílio-maternidade, acidente de trabalho e saúde. Este primeiro fator tende a retratar, em especial, a participação dos aposentados e pensionistas na composição da renda familiar, seja pelo peso populacional dos mesmos na RMSP, seja pela menor incidência estatística da declaração dos demais tipos de rendimentos ou ainda do baixo valor dos mesmos. Trata-se, pois, de um fator sensível aos efeitos da política de reajuste dos benefícios pagos pela Previdência Social (e, portanto, do salário mínimo) e, em menor medida, das ações políticas de minimização dos efeitos negativos do desemprego.

Os três fatores seguintes referem-se diretamente à dinâmica conjuntural do mercado de trabalho, constituindo-se nas principais variáveis de ajuste aos diferentes contextos econômicos vivenciados. O segundo fator no modelo visa indicar a contribuição do trabalho adicional dos indivíduos sobre a renda familiar, medida através do acréscimo proporcionado à renda do trabalho principal. Reflete, pois, as iniciativas de geração adicional de renda em outros empregos, possivelmente pela insuficiência da renda proporcionada pelo trabalho principal. O terceiro e quarto fatores do modelo dispensam um detalhamento maior de seus significados e efeitos sobre a renda fami- 


\begin{tabular}{|c|c|c|}
\hline Fatores & Fórmulas & Descrição \\
\hline Fator 1 & $\frac{\text { Massa de Renda Familiar }}{\text { Massa de Renda de Todos Trabalhos }}$ & $\begin{array}{l}\text { Contribuição das rendas provenientes de outras fontes ou } \\
\text { de outros membros da família em relação às rendas de } \\
\text { todos os trabalhos percebidas pelos membros da família. }\end{array}$ \\
\hline Fator 2 & $\begin{array}{l}\text { Massa de Renda de Todos Trabalhos } \\
\text { Massa de Renda do Trabalho Principal }\end{array}$ & $\begin{array}{l}\text { Contribuição das rendas de todos os trabalhos em relação } \\
\text { à renda do trabalho principal recebida pelos ocupados. }\end{array}$ \\
\hline Fator 3 & $\frac{\text { Massa de Renda do Trabalho Principal }}{\text { Total de Ocupados }}$ & Renda média do trabalho principal dos ocupados. \\
\hline Fator 4 & $\begin{array}{c}\text { Total de Ocupados } \\
\text { Total de Ativos }\end{array}$ & Taxa de ocupação da PEA de 10 anos ou mais. \\
\hline Fator 5 & $\frac{\text { Total de Ativos }}{\text { População de } 10 \text { Anos e Mais }}$ & Taxa de participação da População de 10 anos ou mais. \\
\hline Fator 6 & $\frac{\text { População de } 10 \text { Anos e Mais }}{\text { População Total }}$ & Proporção da População em Idade Ativa na População. \\
\hline
\end{tabular}

Fonte: Árias, 1996

liar per capita, já que representam, respectivamente, o rendimento médio do trabalho principal da população ocupada e a taxa de ocupação da População Economicamente Ativa (PEA).

Os dois últimos fatores estão intrinsecamente ligados a processos socioeconômicos e socioculturais mais estruturais, vinculados a transformações de mais longo prazo na sociedade (Chahad, 1981; Elizaga, 1979). É bem verdade que a taxa de participação - quinto fator do modelo - também é afetada por oscilações conjunturais do mercado de trabalho, mas sua evolução temporal é ditada sobretudo pela transformação das normas socioculturais e institucionais que regulam a participação dos indivíduos - homens e mulheres, chefes e cônjuges, jovens e idosos - no mercado de trabalho. No período em análise, este fator tende a refletir o balanço líquido do aumento da participação feminina e diminuição das taxas de atividade de jovens e homens no mercado de trabalho da RMSP (Ferreira e Aquilini, 1999). Por fim, o sexto e último fator do modelo de decomposição da renda familiar per capita corresponde à proporção de população em idade ativa na população total, que incorpora a contribuição da população potencialmente apta a participar na força de trabalho. Juntamente com a taxa de participação, este fator define o contingente de indivíduos que potencial ou ativamente podem se engajar em atividades produtivas na sociedade. Tal fator - Proporção de População em Idade Ativa - tem seu comportamento condicionado pela dinâmica demográfica passada e presente, refletindo mudanças estruturais que têm se processado durante um longo período na RMSP, como a queda dos níveis de mortalidade, a transição da fecundidade e a relativa diminuição da intensidade migratória interestadual comparativamente aos anos 70 (Fundação Seade, 1993). A introdução deste fator no modelo destina-se a retirar os efeitos composicionais que o envelhecimento populacional exerce sobre a renda.

Assim, o nível da renda familiar per capita em um dado momento é resultado do produto desses seis componentes ou fatores, cada um sujeito a distinta sensibilidade e amplitude de variação a curto, médio e longo prazos. A renda média do trabalho principal e a taxa de ocupação tendem a ser mais sensíveis às variações conjunturais da economia, da produção industrial e da política econômica federal, causando impactos significativos sobre a renda familiar per capita a curto prazo. O componente relacionado à contribuição dos trabalhos adicionais também tem sua dinâmica fortemente condicionada aos movimentos cíclicos da economia, mas apresenta uma amplitude de variação pequena. Os demais fatores do modelo tendem a ser menos elásticos a curto prazo.

É importante notar que, sendo um modelo multiplicativo, a queda de um (ou mais) componente(s) pode 
ser compensada pelo incremento de outros componentes, sem que o produto final, ou seja, a situação média de bemestar da sociedade em estudo se altere. Portanto, é perfeitamente possível que aumentos na taxa de desemprego, que definem uma clara deterioração da situação ocupacional, não ocasionem uma diminuição do bem-estar médio (medido pelo nível de renda familiar per capita), se a renda real do trabalho principal apresentar uma evolução favorável (Árias, 1996). ${ }^{8}$ Tampouco pode se esperar que, por conta do envelhecimento da PIA, a renda familiar per capita inexoravelmente aumente. A diminuição do ritmo de crescimento populacional - a contraface do envelhecimento da PIA - só se traduziria em melhoria do bem-estar médio (expresso em renda média per capita) se os demais fatores não anulassem os efeitos que potencialmente tal fenômeno poderia induzir (menos comensais para uma dada renda familiar). Todavia, o envelhecimento populacional implica também uma eventual diminuição da renda familiar, decorrente da substituição dos rendimentos do trabalho por proventos previdenciários em geral mais baixos.

\section{EVOLUÇÃO CONJUNTURAL DA RENDA FAMILIAR PER CAPITA}

O comportamento da renda familiar per capita na RMSP, nos anos 90, refletiu com grande nitidez as oscilações conjunturais de curto prazo e as mudanças estruturais por que têm passado, no período, a economia e o mercado de trabalho no país (Baltar; Dedecca e Henrique, 1997; Mattoso e Baltar, 1996). Assim, como desdobramento da recessão induzida pelo Plano Collor, a renda familiar per capita apresentou uma queda acentuada entre 1990 e 1992 , recuperando gradativamente seu poder de compra a partir de então, com a retomada das atividades industriais em 1993 e a mudança da política econômica. Com a implantação do Plano Real, a renda familiar per capita elevouse de forma mais significativa, superando em 1995, pela primeira vez, o patamar médio observado no primeiro semestre de 1990. Em 1997, refletindo o desaquecimento geral da economia e sobretudo da indústria, a renda familiar per capita passou a apresentar uma tendência de decrescimento, chegando, ao final de 1998, a um patamar um pouco inferior ao nível médio alcançado no início da década (Tabela 1 e Gráfico 1).

Mais especificamente, no início do período em análise - primeiro semestre de 1990 - a renda familiar média per capita era de cerca de $\mathrm{R} \$ 412$. Dois anos mais tarde, como consequiência da retração da atividade econômica, da persistência de níveis inflacionários relativamente elevados e das restrições aos mecanismos de indexação dos salários, a renda diminuiu, cumulativamente, cerca de $30 \%$, chegando a seu nível mais baixo na década, cerca de $\mathrm{R} \$$ 288 no primeiro semestre de 1992 . Nos semestres seguintes, a renda familiar passou a recuperar sistematicamente as perdas passadas, atingindo nos primeiros meses de 1994 o valor de $\mathrm{R} \$ 364$, cifra $27 \%$ superior àquela apurada no pior momento da década. Ao longo do ano de implantação do Plano Real, a renda familiar média per capita aumentou 16\%, chegando ao patamar de R \$ 420 no primeiro semestre de 1995. Desde então, o nível de renda passou por pequenas oscilações até atingir seu maior valor no período (R\$433) no segundo semestre de 1996. Nos meses que se seguiram, com as medidas governamentais voltadas à desaceleração da atividade econômica no país, passou a haver uma ligeira tendência de queda da renda familiar, de até $3 \%$ a cada semestre, fazendo com que esta chegasse no final de 1998 a um valor de R\$396, cerca de $4 \%$ inferior ao levantado no primeiro semestre de 1990 ( R\$ 413).

A explicação desse comportamento da renda familiar média per capita ao longo da década de 90 deve-se, sobretudo, em termos dos fatores aqui elencados, à trajetória do nível médio da renda do trabalho principal e da taxa de ocupação, principais variáveis de ajuste conjuntural diante das oscilações de curto prazo da economia e das mudanças estruturais no período. ${ }^{9}$ De modo geral, os ou-

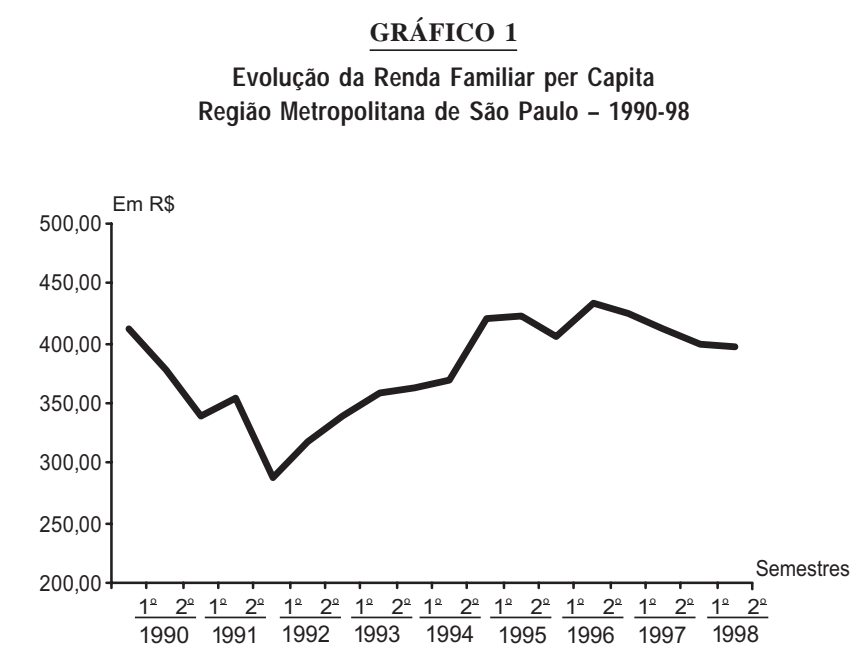

Fonte: SEP. Convênio Seade-Dieese. Pesquisa de Emprego e Desemprego - PED. Nota: Valores deflacionados para abril de 1998 pelo ICV-Dieese. 
TABELA 1

Evolução da Renda Média Familiar per Capita Região Metropolitana de São Paulo - 1990-98

\begin{tabular}{|c|c|c|c|c|}
\hline Anos & Semestres & $\begin{array}{c}\text { Renda Familiar } \\
\text { per Capita (R\$) } \\
\text { (1) }\end{array}$ & $\begin{array}{c}\text { Variação } \\
\text { Semestral (\%) }\end{array}$ & Índice (2) \\
\hline \multirow[t]{2}{*}{1990} & 10 & 412,43 & - & 100,0 \\
\hline & $2^{\circ}$ & 378,88 & $-8,1$ & 91,9 \\
\hline \multirow[t]{2}{*}{1991} & $1^{\circ}$ & 338,57 & $-10,6$ & 82,1 \\
\hline & $2^{0}$ & 353,31 & 4,4 & 85,7 \\
\hline \multirow[t]{2}{*}{1992} & $1^{\circ}$ & 287,52 & $-18,6$ & 69,7 \\
\hline & $2^{\circ}$ & 318,92 & 10,9 & 77,3 \\
\hline \multirow[t]{2}{*}{1993} & $1^{0}$ & 338,92 & 6,3 & 82,2 \\
\hline & $2^{\circ}$ & 358,65 & 5,8 & 87,0 \\
\hline \multirow[t]{2}{*}{1994} & $1^{0}$ & 363,67 & 1,4 & 88,2 \\
\hline & $2^{\circ}$ & 369,60 & 1,6 & 89,6 \\
\hline \multirow[t]{2}{*}{1995} & $1^{0}$ & 420,71 & 13,8 & 102,0 \\
\hline & $2^{\circ}$ & 423,86 & 0,7 & 102,8 \\
\hline \multirow[t]{2}{*}{1996} & $1^{\circ}$ & 406,10 & $-4,2$ & 98,5 \\
\hline & $2^{\circ}$ & 432,80 & 6,6 & 104,9 \\
\hline \multirow[t]{2}{*}{1997} & $1^{\circ}$ & 424,10 & $-2,0$ & 102,8 \\
\hline & $2^{\circ}$ & 412,59 & $-2,7$ & 100,0 \\
\hline \multirow[t]{2}{*}{1998} & $1^{0}$ & 398,89 & $-3,3$ & 96,7 \\
\hline & $2^{0}$ & 396,33 & $-0,6$ & 96,1 \\
\hline
\end{tabular}

Fonte: SEP. Convênio Seade-Dieese. Pesquisa de Emprego e Desemprego - PED. (1) Valores deflacionados para abril de 1998 pelo ICV-Dieese.

(2) Base: $1 \stackrel{0}{ }$ semestre de $1990=100$. tros fatores tiveram papel menos importante nas oscilações conjunturais da renda familiar. Contudo, dada a natureza mais estrutural das dimensões que representam, estes outros fatores tiveram efeitos bastante significativos se avaliados entre os anos extremos do período, contrapondo-se, inclusive, aos efeitos negativos que a evolução desfavorável da renda do trabalho e da taxa de ocupação impôs à renda familiar entre 1990 e 1998 (Tabela 2 e Gráfico 2).

Assim, a acentuada queda da renda familiar entre 1990 e 1992 (30\%) decorreu da não menos drástica diminuição em $29 \%$ da renda média do trabalho principal dos ocupados neste período, combinada com uma redução de 6\% na taxa de ocupação. No interregno seguinte, de 1992 a 1994, a recuperação da renda familiar per capita (27\%) foi quase exclusivamente movida pelo aumento de $26 \%$ da renda do trabalho principal, já que a taxa de ocupação manteve-se em níveis muito próximos àqueles apurados nos piores momentos da recessão dos primeiros anos da década. Aliás, a taxa de ocupação não mais recuperaria, ao longo da década, o patamar alcançado no início do período, ainda que apresentasse variações positivas na implantação do real em 1994.

Para o significativo aumento de $16 \%$ da renda familiar per capita durante o primeiro ano da estabilização econômica, entre 1994 e 1995, contribuíram praticamente todos os fatores. Neste interregno, embora a renda do trabalho e a taxa de ocupação mantivessem a prevalência na

TABELA 2

Comportamento da Renda Familiar per Capita e Variação dos Fatores do Modelo Região Metropolitana de São Paulo - 1990-1998

\begin{tabular}{|c|c|c|c|c|c|c|c|c|c|}
\hline \multirow{3}{*}{ Períodos } & \multicolumn{3}{|c|}{ Renda Familiar per Capita } & \multicolumn{6}{|c|}{ Variação dos Fatores do Modelo (\%) } \\
\hline & $\begin{array}{l}\text { Nível no } \\
\text { Início do } \\
\text { Período } \\
\text { (R\$) }\end{array}$ & $\begin{array}{l}\text { Nível no } \\
\text { Final do } \\
\text { Período } \\
\text { (R\$) }\end{array}$ & $\begin{array}{c}\text { Variação } \\
\text { no Período } \\
(\%)\end{array}$ & $\begin{array}{c}\text { Proporção } \\
\text { da PIA na } \\
\text { População } \\
\text { Total }\end{array}$ & $\begin{array}{c}\text { Taxa de } \\
\text { Participação }\end{array}$ & $\begin{array}{c}\text { Taxa de } \\
\text { Ocupação }\end{array}$ & $\begin{array}{c}\text { Renda } \\
\text { Média do } \\
\text { Trabalho } \\
\text { Principal }\end{array}$ & $\begin{array}{c}\text { Contribuição } \\
\text { de Outros } \\
\text { Trabalhos }\end{array}$ & $\begin{array}{c}\text { Contribuição } \\
\text { de Outras } \\
\text { Rendas }\end{array}$ \\
\hline & (1) & (1) & & & & & & & \\
\hline $1^{0}$ semestre/1990 - 1ำ semestre/1992 & 412,43 & 287,52 & $-30,3$ & 2,1 & 1,4 & $-6,0$ & $-29,3$ & 0,6 & 0,8 \\
\hline $1^{\circ}$ semestre/1992 - 1ำ semestre/1994 & 287,52 & 363,67 & 26,5 & 0,6 & $-1,7$ & 0,1 & 26,4 & $-0,7$ & 1,7 \\
\hline $1^{\circ}$ semestre/1994 - 1ำ semestre/1995 & 363,67 & 420,71 & 15,7 & 1,9 & 3,0 & 3,1 & 7,0 & 1,5 & $-1,5$ \\
\hline 1ㅇsemestre/1995 - 2ㅇsemestre/1996 & 420,71 & 432,80 & 2,9 & 0,3 & 1,0 & $-1,7$ & 1,9 & 0,0 & 1,4 \\
\hline $2^{0}$ semestre/1996 - 2 semestre/1998 & 432,80 & 396,33 & $-8,4$ & 0,4 & $-0,6$ & $-4,6$ & $-5,8$ & $-0,7$ & 2,7 \\
\hline $1^{\circ}$ semestre/1990 - 2 semestre/1998 & 412,43 & 396,33 & $-3,9$ & 5,3 & 3,1 & $-9,0$ & $-8,1$ & 0,6 & 5,2 \\
\hline
\end{tabular}

Fonte: SEP. Convênio Seade-Dieese. Pesquisa de Emprego e Desemprego - PED. (1) Valores deflacionados para abril de 1998 pelo ICV-Dieese. 
GRÁFICO 2

Variação da Renda Familiar per Capita Total, segundo Fatores do Modelo

Região Metropolitana de São Paulo - 1990-1998
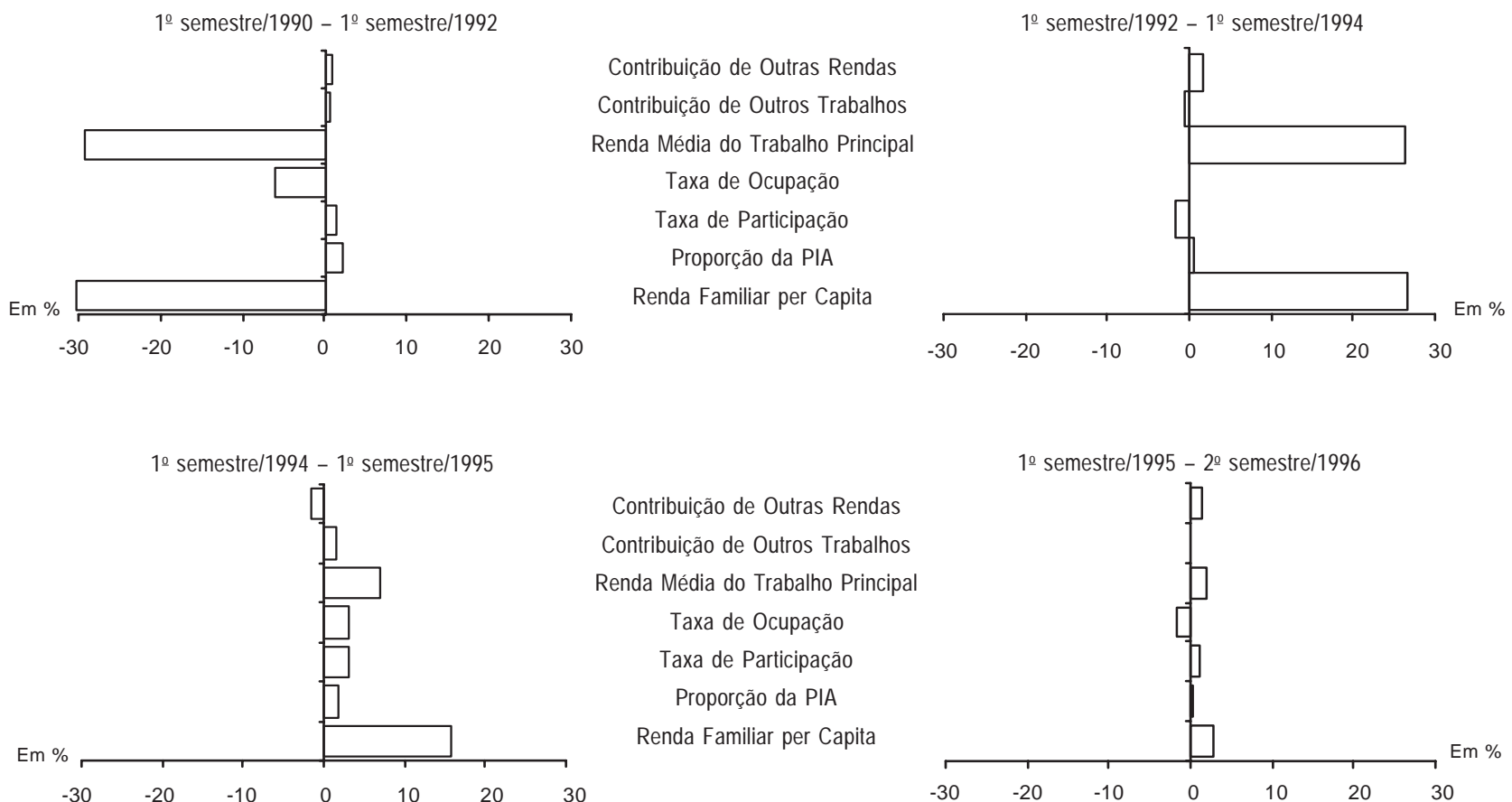

Contribuição de Outras Rendas Contribuição de Outros Trabalhos Renda Média do Trabalho Principal

Taxa de Ocupação

Taxa de Participação

Proporção da PIA

Renda Familiar per Capita
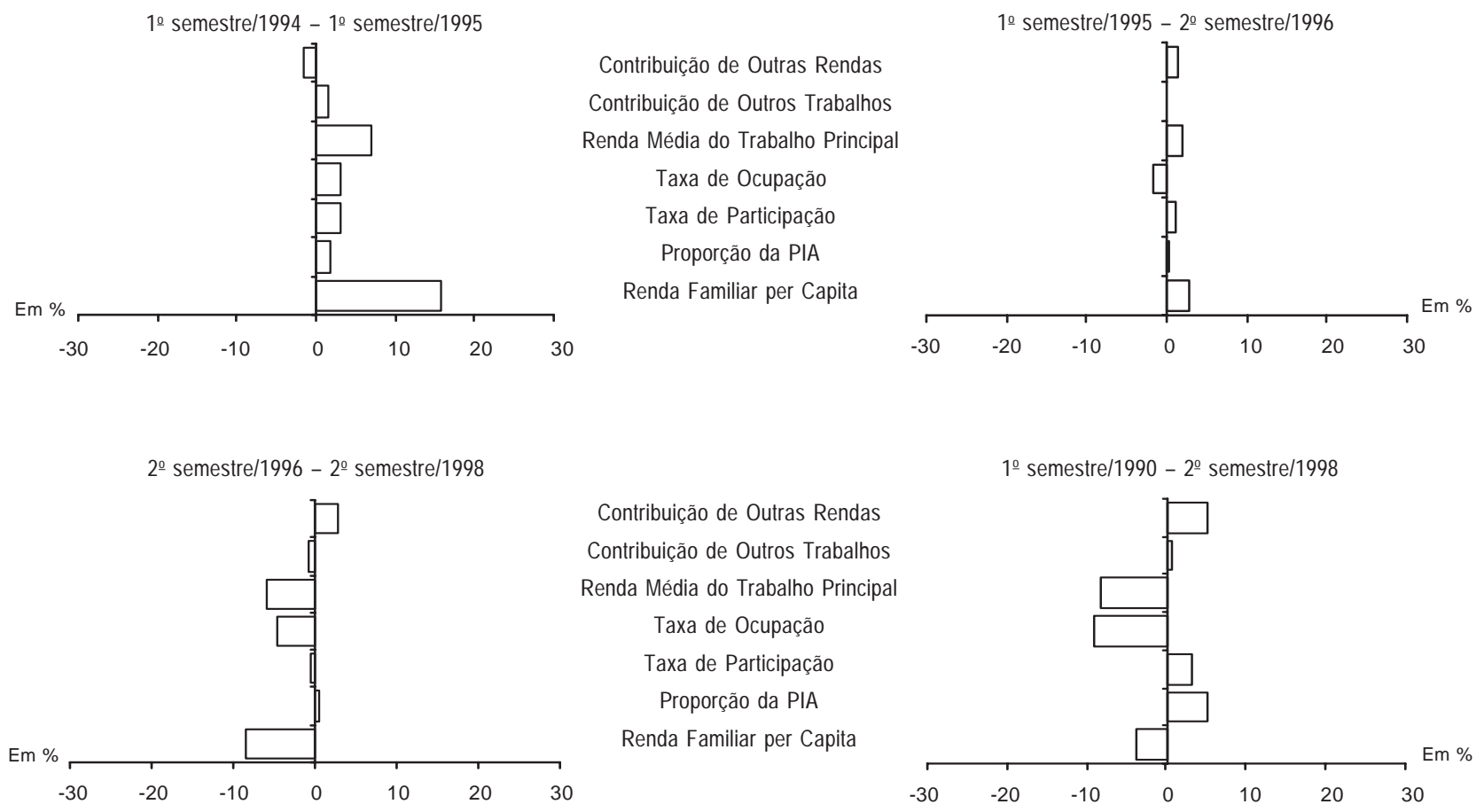

Fonte: SEP. Convênio Seade-Dieese. Pesquisa de Emprego e Desemprego - PED.

determinação do nível média de renda familiar - com aumentos de $7 \%$ e 3\%, respectivamente -, a taxa de participação e a proporção de população em idade ativa apresentaram variações significativas, retratando a retomada da procura por trabalho - movida por condições melhores de mercado - e, possivelmente, a intensificação da migração em direção à Região Metropolitana de São Paulo, como já apontara anteriormente Aranha (1996). Ao longo de 1995 e 1996, com a evolução favorável da renda do trabalho e outros rendimentos, a renda familiar per capita ampliou-se em 3\%. Nos semestres seguintes, a partir de 1997, a queda acentuada e sistemática das taxas de ocupação e da renda do trabalho acabou reduzindo os ganhos obtidos na renda familiar nos dois primeiros anos da estabilização. No último semestre, a taxa de ocupação estava no ponto mais baixo em todo o período analisado - 5 pontos percentuais menor que a apurada no segundo semestre de 1996 e 9 pontos percentuais menor que a veri- 
ficada no início da década. Tendência semelhante foi observada quanto à renda do trabalho: redução de $6 \%$ nos últimos quatro semestres.

Contabilizando as variações conjunturais positivas e negativas entre 1990 e 1998, a renda média do trabalho principal e a taxa de ocupação tiveram um efeito depressor sobre o nível da renda familiar média per capita, já que, entre 1990 e 1998, esses componentes apresentaram uma diminuição de $8 \%$ e $9 \%$, respectivamente. A perda de valor real de compra da renda familiar per capita só não foi maior porque houve ampliação significativa da contribuição de outras rendas (aumento de 5\%), como conseqüência certamente do aumento real do valor das aposentadorias e pensões e do número de beneficiários da Previdência Social (Batich e Marques, 1998). Ao longo da década, como já sugeriam as tendências apontadas por Bercovich; Madeira e Torres (1998), a PIA e, em menor medida, a PEA registraram aumentos significativos, como revelam as variações positivas de $5 \%$ da proporção da PIA sobre a população total e de $3 \%$ da taxa de participação.

\section{DISTRIBUIÇÃO DA RENDA FAMILIAR}

Em função de suas características sociodemográficas, cada estrato socioeconômico de indivíduos apresenta um padrão específico de taxa de participação, taxa de ocupação e dos demais fatores, que se combinam para "determinar" um certo nível de renda familiar per capita. Assim, ao final de 1998 , entre os $20 \%$ mais pobres, a proporção da PIA em relação à população total era de cerca de $71 \%$, valor este mais baixo que nos demais quintis, especialmente quanto aos $20 \%$ mais ricos, em que tal fator atingia $89 \%$ no mesmo período. Com relação às taxas de participação, e de ocupação, à renda média do trabalho e à contribuição dos demais trabalhos, também se observa um gradiente de variação crescente do primeiro ao último quintil. Entre os $20 \%$ mais pobres, a taxa de ocupação era de $52 \%$, patamar bastante inferior ao atingido pelos $20 \%$ mais ricos (95\%). Quanto ao fator associado à contribuição de outras rendas, a relação é inversa: entre os $20 \%$ mais pobres, as rendas provenientes de aposentadorias, pensões, auxílios previdenciários e seguro-desemprego correspondem a um adicional de $31 \%$ sobre a massa de rendimentos do trabalho; nos demais quintis, essa cifra vai diminuindo até chegar a $12 \%$ entre os $20 \%$ mais ricos (Tabela 3 ).

Em que pesem estas diferenças de nível entre os fatores pelos quintis de renda, o comportamento da renda familiar per capita nos mesmos seguiu, em grandes linhas, as tendências anteriormente descritas, vinculando-se aos movimentos cíclicos da economia nacional no período. ${ }^{10}$ Ainda assim, há algumas nuanças importantes a apontar e que explicam o agravamento do perfil distributivo entre 1990 e 1998 . Enquanto os $20 \%$ mais pobres auferiam uma renda per capita $13 \%$ menor no segundo semestre de 1998 que aquela levantada no início do período, os 20\% mais ricos haviam conseguido até mesmo ampliá-la em cerca de $4 \%$. É curiosa a regularidade da variação da renda ao longo dos 18 semestres pelos quintis de renda: tão maior quanto maior a renda. Neste sentido, parece razoável analisar mais detalhamente a evolução da renda per capita das famílias situadas nos dois quintis extremos, in-

TABELA 3

Nível Médio dos Fatores do Modelo, segundo Quintis de Renda Região Metropolitana de São Paulo - 2º semestre de 1998

\begin{tabular}{lccccccc}
\hline Estratos & $\begin{array}{c}\text { Renda } \\
\text { Familiar } \\
\text { per Capita } \\
(\mathrm{R} \$)(1)\end{array}$ & $\begin{array}{c}\text { Proporção } \\
\text { da PIA na } \\
\text { População } \\
\text { Total (\%) }\end{array}$ & $\begin{array}{c}\text { Taxa de } \\
\text { Participação } \\
(\%)\end{array}$ & $\begin{array}{c}\text { Taxa de } \\
\text { Ocupação } \\
(\%)\end{array}$ & $\begin{array}{c}\text { Renda } \\
\text { Média do } \\
\text { Trabalho } \\
\text { Principal (R\$) (1) }\end{array}$ & $\begin{array}{c}\text { Contribuição } \\
\text { de Outros } \\
\text { Trabalhos }\end{array}$ & $\begin{array}{c}\text { Contribuição } \\
\text { de Outras } \\
\text { Rendas }\end{array}$ \\
\hline Total & 396,33 & 81,1 & 60,3 & 80,4 & 846,52 & 1,036 & 1,149 \\
10 Quintil & 51,92 & 71,3 & 48,6 & 52,4 & 215,85 & 1,008 & 1,311 \\
20 Quintil & 145,86 & 78,3 & 57,5 & 75,7 & 346,62 & 1,014 & 1,218 \\
30 Quintil & 252,73 & 83,1 & 61,9 & 83,7 & 484,54 & 1,018 & 1,190 \\
40 Quintil & 450,06 & 87,8 & 66,5 & 89,8 & 719,54 & 1,025 & 1,164 \\
50 Quintil & $1.361,31$ & 89,2 & 69,1 & 95,0 & $1,986,67$ & 1,048 & 1,117 \\
\hline
\end{tabular}

Fonte: SEP. Convênio Seade-Dieese. Pesquisa de Emprego e Desemprego - PED. (1) Valores deflacionados para abril de 1998 pelo ICV-Dieese. 
ferindo-se para os grupos intermediários tendências próximas de um ou outro quintil (Tabela 4).

Embora a renda familiar per capita dos indivíduos situados no primeiro quintil de renda tivesse apresentado um comportamento tendencialmente próximo da trajetória descrita para a renda média ao longo da década, esta sofreu oscilações conjunturais, em geral, mais acentuadas nos períodos cíclicos e anticíclicos da economia nacional e paulista. Depois de significativa queda durante os primeiros anos da década, foi só no final de 1995 que a renda média dos $20 \%$ mais pobres recuperou o poder de compra observado em 1990.

As perdas acumuladas durante o período recessivo de 1991-92 explicam, em boa medida, as dificuldades posteriores de recuperação do valor real da renda familiar dos mais pobres. Afinal, entre 1990 e 1992, a renda per capita passou de $\mathrm{R} \$ 60$ para $\mathrm{R} \$ 39$, acumulando uma perda de $34 \%$, quatro pontos percentuais mais elevada que a observada para a renda média per capita da RMSP (30\%).
Respondeu por tal comportamento, além da diminuição da renda do trabalho principal em $29 \%$, a forte redução da taxa de ocupação dos indivíduos deste estrato de renda, que passou de $70 \%$ para $57 \%$ da população economicamente ativa no interregno. Em termos relativos, a diminuição da taxa de ocupação foi de $19 \%$, muito mais elevada que a observada na média geral $(6 \%)$. A queda da renda familiar per capita deste grupo só não foi maior por conta do aumento (8\%), em igual período, da parcela adicional gerada por outras rendas e membros ${ }^{11}$ (Tabela 5 e Gráfico 3).

Com a dinamização da atividade econômica a partir de 1993, a renda familiar per capita dos $20 \%$ mais pobres recuperou gradativamente seu poder de compra, mas não com a intensidade observada para a população em geral. Entre 1992 e 1994, com a renda do trabalho principal crescendo a taxas mais baixas que a do conjunto dos ocupados, a renda familiar aumentou $20 \%$, sete pontos percentuais abaixo da média geral. Nos primeiros anos da

TABELA 4

Evolução da Renda Familiar per Capita, por Quintis

Região Metropolitana de São Paulo - 1990-98

\begin{tabular}{|c|c|c|c|c|c|c|c|c|}
\hline \multirow{3}{*}{ Anos } & \multirow{3}{*}{ Semestres } & \multicolumn{6}{|c|}{ Renda Familiar per Capita (R\$) (1) } & \multirow{3}{*}{$\begin{array}{r}\text { Razão } \\
\text { 5 Quintil } \\
\text { 1ㅇ Quintil }\end{array}$} \\
\hline & & \multirow{2}{*}{$1^{\circ}$ Quintil } & \multirow{2}{*}{$2^{\circ}$ Quintil } & \multirow{2}{*}{ 3 Quintil } & \multirow{2}{*}{$4^{\circ}$ Quintil } & \multirow{2}{*}{$5^{\circ}$ Quintil } & \multirow{2}{*}{ Média } & \\
\hline & & & & & & & & \\
\hline \multirow[t]{2}{*}{1990} & $1^{0} \underline{0}$ & 59,62 & 163,75 & 277,91 & 479,32 & $1.312,47$ & 412,43 & 22,0 \\
\hline & $2^{0}$ & 60,18 & 157,58 & 259,02 & 434,50 & $1.169,89$ & 378,88 & 19,4 \\
\hline \multirow[t]{2}{*}{1991} & 10 & 49,61 & 137,04 & 229,73 & 390,79 & $1.075,83$ & 338,57 & 21,7 \\
\hline & $2^{0}$ & 56,86 & 146,49 & 242,21 & 411,62 & $1.092,10$ & 353,31 & 19,2 \\
\hline \multirow[t]{2}{*}{1992} & $1^{0}$ & 39,29 & 114,36 & 193,59 & 332,68 & 903,31 & 287,52 & 23,0 \\
\hline & $2^{0}$ & 45,42 & 124,87 & 212,16 & 367,55 & $1.035,51$ & 318,92 & 22,8 \\
\hline \multirow[t]{2}{*}{1993} & 10 & 46,32 & 132,38 & 226,19 & 392,67 & $1.114,24$ & 338,92 & 24,1 \\
\hline & $2^{0}$ & 53,64 & 139,50 & 236,86 & 410,45 & $1.178,49$ & 358,65 & 22,0 \\
\hline \multirow[t]{2}{*}{1994} & $1^{0}$ & 46,95 & 131,76 & 233,06 & 416,59 & $1.198,07$ & 363,67 & 25,5 \\
\hline & $2^{0}$ & 48,26 & 132,51 & 230,34 & 415,58 & $1.232,99$ & 369,60 & 25,5 \\
\hline \multirow[t]{2}{*}{1995} & $1^{0}$ & 58,83 & 156,08 & 266,50 & 465,32 & $1.389,30$ & 420,71 & 23,6 \\
\hline & $2^{0}$ & 60,90 & 162,15 & 274,64 & 479,10 & $1.381,81$ & 423,86 & 22,7 \\
\hline \multirow[t]{2}{*}{1996} & 10 & 55,48 & 152,90 & 259,62 & 454,34 & $1.340,06$ & 406,10 & 24,2 \\
\hline & $2^{0}$ & 63,58 & 165,12 & 278,18 & 486,48 & $1.443,81$ & 432,80 & 22,7 \\
\hline \multirow[t]{2}{*}{1997} & $1^{0}$ & 58,05 & 157,88 & 269,61 & 481,39 & $1.418,89$ & 424,10 & 24,4 \\
\hline & $2^{0}$ & 55,56 & 151,47 & 259,35 & 461,29 & $1.398,45$ & 412,59 & 25,2 \\
\hline \multirow[t]{2}{*}{1998} & $1^{0}$ & 50,29 & 144,65 & 250,25 & 444,87 & $1.342,24$ & 398,89 & 26,7 \\
\hline & $2^{\circ}$ & 51,92 & 145,86 & 252,73 & 450,06 & $1.361,31$ & 396,33 & 26,2 \\
\hline \multicolumn{9}{|c|}{ Índices (2) } \\
\hline 1990 & $1^{0}$ & 100,0 & 100,0 & 100,0 & 100,0 & 100,0 & 100,0 & 100,0 \\
\hline 1992 & $1^{0}$ & 65,9 & 69,8 & 69,7 & 69,4 & 68,8 & 69,7 & 104,4 \\
\hline 1994 & 10 & 78,8 & 80,5 & 83,9 & 86,9 & 91,3 & 88,2 & 115,9 \\
\hline 1995 & $1^{0}$ & 98,7 & 95,3 & 95,9 & 97,1 & 105,9 & 102,0 & 107,3 \\
\hline 1996 & $2^{\circ}$ & 106,6 & 100,8 & 100,1 & 101,5 & 110,0 & 104,9 & 103,2 \\
\hline 1998 & $2^{0}$ & 87,1 & 89,1 & 90,9 & 93,9 & 103,7 & 96,1 & 119,1 \\
\hline
\end{tabular}

Fonte: SEP. Convênio Seade-Dieese. Pesquisa de Emprego e Desemprego - PED.

(1) Valores deflacionados para abril de 1998 pelo ICV-Dieese.

(2) Base: 1ำ semestre de 1990=100. 
TABELA 5

Renda Familiar per Capita dos $20 \%$ mais Pobres e dos $20 \%$ mais Ricos e Variação dos Fatores do Modelo Região Metropolitana de São Paulo - 1990-1998

\begin{tabular}{|c|c|c|c|c|c|c|c|c|c|}
\hline \multirow[b]{2}{*}{ Períodos } & \multicolumn{3}{|c|}{ Renda Familiar per Capita } & \multicolumn{6}{|c|}{ Variação dos Fatores do Modelo (\%) } \\
\hline & $\begin{array}{l}\text { Nível no } \\
\text { Início do } \\
\text { Período (R\$) } \\
\text { (1) }\end{array}$ & $\begin{array}{c}\text { Nível no } \\
\text { Final do } \\
\text { Período (R\$) } \\
\text { (1) }\end{array}$ & $\begin{array}{c}\text { Variação no } \\
\text { Período } \\
(\%)\end{array}$ & $\begin{array}{c}\text { Proporção da } \\
\text { PIA na } \\
\text { População } \\
\text { Total }\end{array}$ & $\begin{array}{l}\text { Taxa de } \\
\text { Participação }\end{array}$ & $\begin{array}{l}\text { Taxa de } \\
\text { Ocupação }\end{array}$ & $\begin{array}{l}\text { Renda } \\
\text { Média do } \\
\text { Trabalho } \\
\text { Principal }\end{array}$ & $\begin{array}{c}\text { Contribuição } \\
\text { de Outros } \\
\text { Trabalhos }\end{array}$ & $\begin{array}{c}\text { Contribuição } \\
\text { de Outras } \\
\text { Rendas }\end{array}$ \\
\hline \multicolumn{10}{|l|}{$20 \%$ mais Pobres } \\
\hline 1ㅇ semestre/1990 - 1ㅇsemestre/1992 & 59,62 & 39,29 & $-34,1$ & 2,8 & 2,3 & $-18,5$ & $-29,0$ & $-0,1$ & 8,4 \\
\hline 1ํ semestre/1992 - 1ํ semestre/1994 & 39,29 & 46,95 & 19,5 & $-1,1$ & 0,8 & 4,1 & 18,0 & 0,2 & $-2,6$ \\
\hline $1^{0}$ semestre/1994 - 1º semestre/1995 & 46,95 & 58,83 & 25,3 & 2,7 & $-2,3$ & 7,9 & 15,1 & 0,6 & 0,0 \\
\hline 1ㅇ semestre/1995 - 2ㅇ semestre/1996 & 58,83 & 63,58 & 8,1 & $-0,4$ & 3,0 & $-3,6$ & 14,1 & $-0,5$ & $-3,8$ \\
\hline $2^{0}$ semestre/1996 - 2ㅇ semestre/1998 & 63,58 & 51,92 & $-18,3$ & $-0,6$ & $-0,6$ & $-15,5$ & $-7,5$ & $-0,5$ & 6,4 \\
\hline $1^{\circ}$ semestre/1990 - 2o semestre/1998 & 59,62 & 51,92 & $-12,9$ & 3,4 & 3,2 & $-25,4$ & 1,7 & $-0,4$ & 8,0 \\
\hline \multicolumn{10}{|l|}{$20 \%$ mais Ricos } \\
\hline $1^{\circ}$ semestre/1990 - 1ㅇ semestre/1992 & $1.312,47$ & 903,31 & $-31,2$ & 1,2 & 1,7 & $-1,7$ & $-32,0$ & 0,8 & $-0,7$ \\
\hline $1^{\circ}$ semestre/1992 - 1ํ semestre/1994 & 903,31 & $1.198,07$ & 32,6 & 0,3 & $-3,7$ & $-0,2$ & 36,7 & $-1,3$ & 2,0 \\
\hline 1ㅇ semestre/1994 - 1ㅇ semestre/1995 & $1.198,07$ & $1.389,30$ & 16,0 & 1,1 & 3,4 & 1,0 & 9,0 & 2,2 & $-1,4$ \\
\hline $1^{\circ}$ semestre/1995 - 2º semestre/1996 & $1.389,30$ & $1.443,81$ & 3,9 & 1,1 & 2,3 & 0,2 & $-0,5$ & $-0,3$ & 1,0 \\
\hline $2^{\circ}$ semestre/1996 - $2^{\circ}$ semestre/1998 & $1.443,81$ & $1.361,31$ & $-5,7$ & 1,5 & $-0,7$ & $-0,9$ & $-7,1$ & $-0,8$ & 2,5 \\
\hline 1ㅇ semestre/1990 - 20 semestre/1998 & $1.312,47$ & $1.361,31$ & 3,7 & 5,3 & 2,9 & $-1,7$ & $-6,4$ & 0,6 & 3,3 \\
\hline
\end{tabular}

Fonte: SEP. Convênio Seade-Dieese. Pesquisa de Emprego e Desemprego - PED. (1) Valores deflacionados para abril de 1998 pelo ICV-Dieese.

estabilização econômica (de 1994 a 1996), contudo, a renda per capita das famílias mais pobres elevou-se de forma significativa, alcançando, no segundo semestre de 1996, o seu maior valor na década ( $\mathrm{R}$ \$ 64), impulsionada pela recuperação do valor real da renda média dos ocupados. A recuperação do valor real da renda dessas famílias foi mais intensa que a média do conjunto tanto no primeiro como no segundo ano do Plano Real. Entre 1994 e 1995 , a renda familiar dos $20 \%$ mais pobres aumentou $25 \%$, cifra muito superior ao desempenho da renda média do conjunto (16\%). Nos três semestres seguintes, acumulou uma variação positiva de $8 \%$ (contra um aumento de $3 \%$ para o conjunto da população).

A partir de 1997, as medidas governamentais de contenção da atividade econômica e as restrições sistêmicas ao crescimento da produção repercutiram de forma mais intensa sobre o nível de salários e de empregos das famílias mais pobres. Ao longo dos últimos quatro semestres, a renda acumularia uma perda de $18 \%$. De forma semelhante ao ocorrido na recessão de 1991-92, a redução do valor médio da renda dessas famílias decorreu da forte queda $(16 \%)$ da taxa de ocupação no período e da diminuição $(8 \%)$ - bem menos intensa, desta vez - da renda do trabalho. Contrapôs-se a essa diminuição o aumento da contribuição de rendas provenientes de outras fontes que não diretamente do trabalho, seja pelo aumento real do valor das aposentadorias e pensões, seja pelo efeito aritmético decorrente da diminuição do denominador (rendas do trabalho) na sua computação.

Considerando os anos extremos do intervalo de tempo em análise, a queda do nível de ocupação foi o principal determinante da redução do valor da renda per capita dos mais pobres. A diminuição da taxa de ocupação de $70 \%$ para 57\% da PEA, entre 1990 e 1997, provocou um efeito depressor muito mais intenso sobre a renda per capita do que o efeito expansor proporcionado pelos pequenos ganhos reais da renda do trabalho e os avanços mais estruturais obtidos nos demais fatores na década.

Se é verdade que os $20 \%$ mais ricos também estiveram sujeitos aos dissabores conjunturais da década, foram eles que menor impacto sentiram nos momentos de retração econômica e que mais rapidamente conseguiram recuperar as perdas sofridas no valor dos rendimentos. Constituíram também, como já se observou, o único conjunto, dentre os cinco estratos analisados, que conseguiu preservar e até mesmo ampliar a renda familiar per capita até o final do período. Assim, entre 1990 e 1992, a perda acumulada da renda pelos $20 \%$ mais ricos foi de $31 \%$, sendo parcialmente recuperada no interregno seguinte. Tal elevação, combinada com o aumento generalizado da renda média no ano de implantação do Plano Real, garantiu, já no início de 1995, a recuperação do patamar de renda 


\section{GRÁFICO 3}

Variação da Renda Familiar per Capita dos 20\% mais Pobres e dos 20\% mais Ricos, segundo Fatores do Modelo

Região Metropolitana de São Paulo - 1990-1998

| $20 \%+$ + Ricos $\quad \square 20 \%+$ Pobres
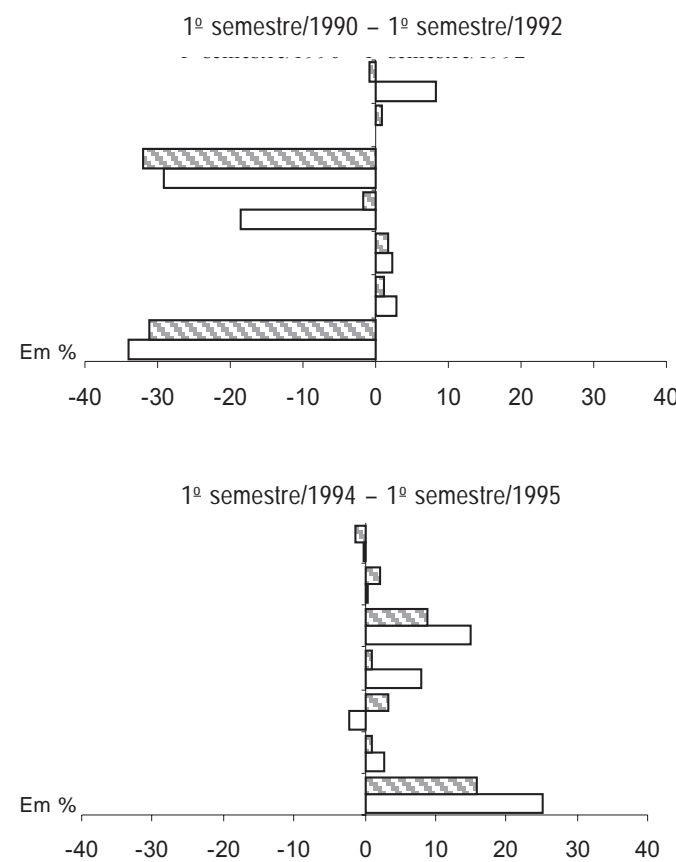

2o semestre/1996 - 2o semestre/1998

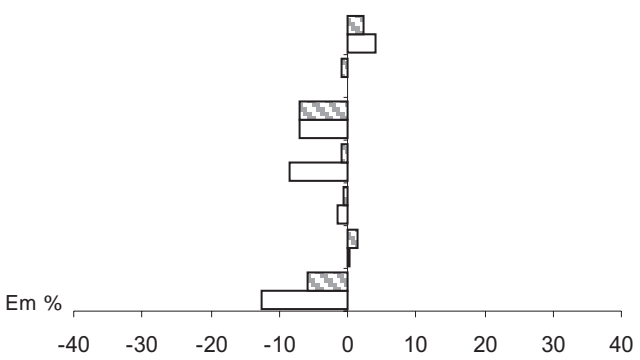

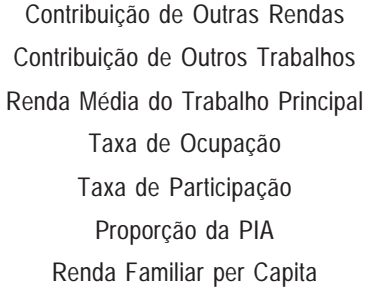

1ํ semestre/1992 - 1o semestre/1994
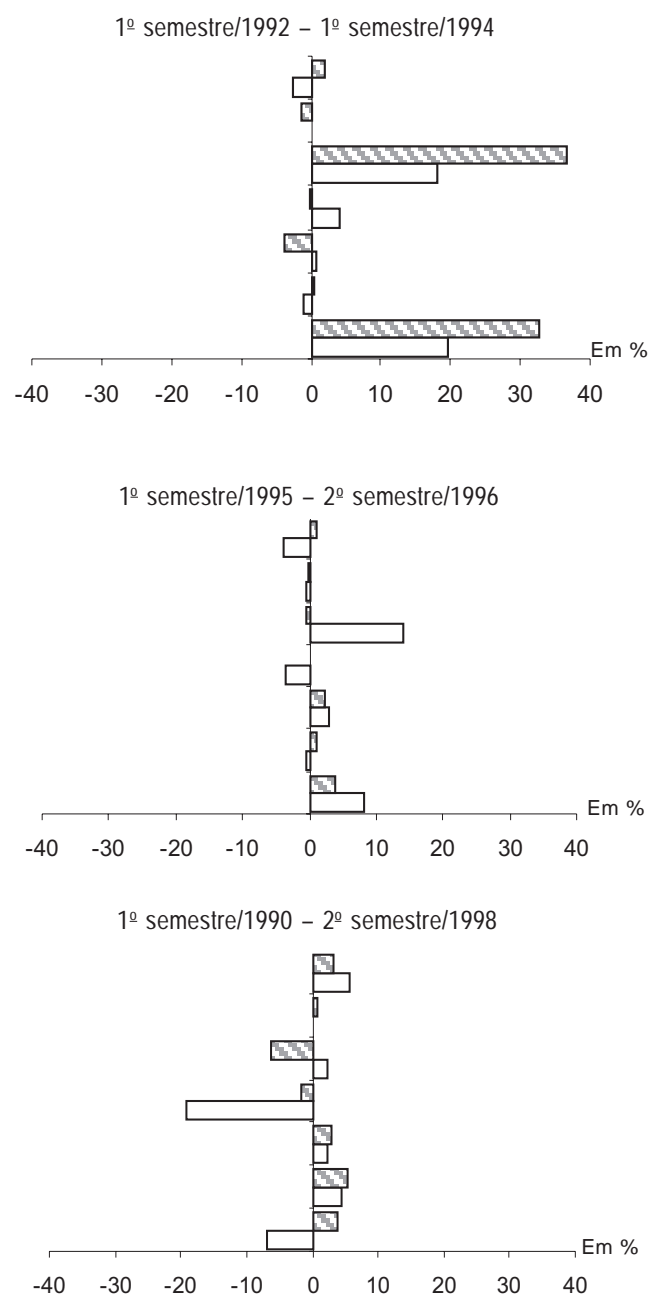

Fonte: SEP. Convênio Seade-Dieese. Pesquisa de Emprego e Desemprego - PED.

per capita vigente em 1990, algo que para os demais indivíduos só ocorreria nos semestres seguintes.

A explicação para tal comportamento da renda deve-se, sobretudo, à evolução mais favorável da taxa de ocupação dentre os indivíduos pertencentes ao estrato mais rico em relação tanto à média do conjunto quanto aos demais estratos. A maior queda da taxa de ocupação foi inferior a $2 \%$, observada entre 1990 e 1992 . Ao longo do período, a redução foi da mesma magnitude e, portanto, muito inferior à variação observada no conjunto das famílias da região - em que se verificou uma queda de $9 \%$ na taxa de ocupação - e à dos $20 \%$ mais pobres ( $25 \%$ de redução).

Como decorrência do comportamento mais virtuoso da renda familiar per capita dos estratos de maior poder aquisitivo (Tabela 4), o perfil distributivo tendeu a se agravar no período, ainda que, nos dois primeiros anos do Plano Real, se observasse uma pequena melhoria. No primeiro semestre de 1990, a renda média per capita dos $20 \%$ mais ricos era 22 vezes maior que a dos $20 \%$ mais pobres. Oito anos depois, no último semestre, esta razão subira para 
26, depois de oscilar entre 23 e 25 no período. Ao longo dos semestres que se seguiram ao Plano Real, a razão de quintis de renda per capita apresentou uma queda de $8 \%$ (entre 1994 e 1995) e de 4\% (entre 1995 e 1996). Contudo, nos dois últimos anos, observou-se um agravamento mais acentuado da desigualdade de renda entre ricos e pobres (15\% a mais), percentual superior ao levantado em outros momentos aqui investigados.

Como já se poderia intuir pelas exposições anteriores, esse agravamento do perfil distributivo decorreu da evolução diferenciada do nível de ocupação entre os mais ricos e os mais pobres. De fato, a taxa de ocupação dos $20 \%$ mais ricos era, ao final do período em análise, de cerca de $95 \%$, enquanto para os $20 \%$ mais pobres era de $52 \%$ (Tabela 4). No entanto, no primeiro semestre de 1990, essas taxas eram de $97 \%$ e $70 \%$, respectivamente (Dini et alii, 1999). Vale observar que, ao contrário do que se poderia imaginar, o comportamento diferencial da renda do trabalho foi um fator que atenuou a tendência de aumento da desigualdade. Enquanto, para os indivíduos mais pobres, a renda do trabalho praticamente manteve seu nível (na comparação entre início e final de período), para os mais ricos houve até mesmo uma pequena redução $(6 \%)$. Isto é, dentre os $20 \%$ mais pobres, aqueles que preservaram seu emprego ou trabalho conseguiram garantir uma remuneração até melhor, em média.

$\mathrm{O}$ aumento mais acentuado da contribuição das demais rendas entre os $20 \%$ mais pobres foi outro fator a atenuar a piora do quadro distributivo da renda familiar per capita. No primeiro semestre de 1990, as rendas não provenientes do trabalho atual somavam um montante que equivalia a $21 \%$ da massa de rendimentos de todos os trabalhos. Ao final do período, esta cifra já aumentara para $31 \%$. Tal fato demonstra a importância que teve o reajuste dos benefícios previdenciários (e do salário mínimo, portanto) em níveis acima da inflação no período como instrumento redistributivo de renda e mesmo para garantir perdas menores de renda per capita para a população menos favorecida, para a qual, vale lembrar, estes rendimentos têm peso proporcionalmente maior (Fundação Seade, 1999).

\section{EVOLUÇÃO DA INDIGÊNCIA NA RMSP}

Ainda que não se possa empregar a fonte de dados aqui analisada - Pesquisa de Emprego e Desemprego - para dimensionar a situação de indigência e pobreza ${ }^{12}$ da população metropolitana, em decorrência de sua não exaustividade na cobertura de outras formas de rendimento, a metodolo- gia aqui apresentada parece útil e pertinente para acompanhamento conjuntural da renda per capita de grupos sociais mais vulneráveis a tal condição. Pode-se analisar a evolução da renda e demais componentes do modelo relativos a cada grupo sociodemográfico, comparando-os com os indicadores médios da população ou ainda com o custo da cesta básica, de forma a poder inferir sobre a vulnerabilidade de cada grupo ao longo do período.

Assim, neste tópico, apresenta-se a evolução comparativa da renda per capita de dois destes grupos mais vulneráveis à condição de indigência - indivíduos que compõem o $1^{\circ}$ quintil de renda per capita (20\% mais pobres) e aqueles pertencentes a famílias com chefe desempregado - diante da evolução do custo de uma cesta básica de alimentos, construída a partir dos parâmetros usados pela Cepal e valorada mensalmente a partir dos preços individuais dos produtos coletados na pesquisa do Índice de Custo de Vida do Dieese (Dini et alii, 1999). ${ }^{13}$

A análise da evolução da renda familiar per capita destes grupos sugere que o grau de indigência da população metropolitana tem diminuído sensivelmente a partir de 1995, depois de atingir patamares mais elevados em meados do primeiro qüinquiênio, como apontaram outros autores (Rocha, 1996; Brandão e Jannuzzi, 1995). O "gap" entre o custo da cesta básica e a renda média per capita dos $20 \%$ mais pobres foi se estreitando nos últimos anos. Ou de forma equivalente, o poder aquisitivo do conjunto dos indivíduos mais pobres, medido em relação ao custo da cesta básica, ficou maior ao final do período, seja em relação a 1990 (cerca de $12 \%$ maior), seja especialmente em relação ao momento mais agudo da recessão no governo Collor (cerca de 50\% de aumento do poder aquisitivo). Este ganho de poder de compra de alimentos básicos pela população de baixa renda - e por conseguinte, a diminuição do grau de indigência - decorreu, por um lado, da diminuição do custo da cesta de alimentos, que passou de $\mathrm{R} \$ 79$ para $\mathrm{R} \$ 63$ per capita entre 1990 e 1997, acusando uma queda de $20 \%$ no período, e, por outro, da elevação do nível médio da renda familiar per capita deste grupo (pelo menos em relação ao período de 1991-92). Vale observar, inclusive, que a diminuição dos custos da cesta foi suficientemente intensa nos últimos anos para compensar, inclusive, a redução de $7 \%$ da renda per capita das famílias mais pobres nos últimos semestres (Tabela 6).

Análise semelhante para famílias com chefes desempregados sugere que, em que pesem as perdas decorrentes da ausência de rendas regulares provenientes do trabalho dos mesmos, o poder de compra da família (em termos de cestas 
TABELA 6

Evolução da Renda Familiar per Capita, por Grupos Vulneráveis

Região Metropolitana de São Paulo - 1990-97

\begin{tabular}{|c|c|c|c|c|c|c|c|c|}
\hline \multirow[b]{2}{*}{ Anos } & \multirow[b]{2}{*}{ Semestres } & \multicolumn{2}{|c|}{ Renda per Capita $(\mathrm{R} \$)(1)$} & \multirow{2}{*}{$\begin{array}{l}\text { Valor Real } \\
\text { do Salário } \\
\text { Mínimo } \\
(\mathrm{R} \$) \\
(1)\end{array}$} & \multirow{2}{*}{$\begin{array}{c}\text { Custo Real } \\
\text { da Cesta } \\
\text { Básica per } \\
\text { Capita (R\$) } \\
\text { (1) }\end{array}$} & \multicolumn{3}{|c|}{ Poder de Compra (2) } \\
\hline & & $\begin{array}{c}20 \% \text { mais } \\
\text { Pobres }\end{array}$ & $\begin{array}{l}\text { Famílias com } \\
\text { Chefe } \\
\text { Desempregado }\end{array}$ & & & $\begin{array}{c}\text { Dos } 20 \% \\
\text { mais Pobres }\end{array}$ & $\begin{array}{l}\text { Das Famílias } \\
\text { com Chefe } \\
\text { Desempregado }\end{array}$ & $\begin{array}{c}\text { Do Salário } \\
\text { Mínimo }\end{array}$ \\
\hline \multirow[t]{2}{*}{1990} & $1^{0}$ & 59,62 & 108,70 & 104,30 & 80,70 & 0,74 & 1,35 & 1,29 \\
\hline & $2^{o}$ & 60,18 & 128,19 & 99,90 & 70,70 & 0,85 & 1,81 & 1,41 \\
\hline \multirow[t]{2}{*}{1991} & $1^{\circ}$ & 49,61 & 98,57 & 128,00 & 65,90 & 0,75 & 1,50 & 1,94 \\
\hline & $2^{\circ}$ & 56,86 & 113,86 & 131,30 & 65,40 & 0,87 & 1,74 & 2,01 \\
\hline \multirow[t]{2}{*}{1992} & $1^{\circ}$ & 39,29 & 90,02 & 115,70 & 65,60 & 0,60 & 1,37 & 1,76 \\
\hline & $2^{\circ}$ & 45,42 & 91,80 & 101,70 & 68,70 & 0,66 & 1,34 & 1,48 \\
\hline \multirow[t]{2}{*}{1993} & $1^{0}$ & 46,32 & 105,50 & 118,90 & 70,00 & 0,66 & 1,51 & 1,70 \\
\hline & $2^{o}$ & 53,64 & 104,04 & 120,60 & 69,30 & 0,77 & 1,50 & 1,74 \\
\hline \multirow[t]{2}{*}{1994} & $1^{0}$ & 46,95 & 94,49 & 118,50 & 72,40 & 0,65 & 1,31 & 1,64 \\
\hline & $2^{o}$ & 48,26 & 107,01 & 83,00 & 75,80 & 0,64 & 1,41 & 1,09 \\
\hline \multirow[t]{2}{*}{1995} & $1^{0}$ & 58,83 & 130,10 & 88,60 & 74,50 & 0,79 & 1,75 & 1,19 \\
\hline & $2^{o}$ & 60,90 & 135,78 & 108,00 & 67,80 & 0,90 & 2,00 & 1,59 \\
\hline \multirow[t]{2}{*}{1996} & $1^{\circ}$ & 55,48 & 127,69 & 109,20 & 66,10 & 0,84 & 1,93 & 1,65 \\
\hline & $2^{\circ}$ & 63,58 & 136,32 & 114,50 & 63,30 & 1,00 & 2,15 & 1,81 \\
\hline \multirow[t]{2}{*}{1997} & $1^{0}$ & 58,05 & 138,47 & 116,80 & 62,70 & 0,93 & 2,21 & 1,86 \\
\hline & $2^{0}$ & 55,56 & 117,61 & 122,10 & 61,30 & 0,91 & 1,92 & 1,99 \\
\hline
\end{tabular}

Fonte: SEP. Convênio Seade-Dieese. Pesquisa de Emprego e Desemprego - PED.

(1) Valores deflacionados para abril de 1998 pelo ICV-Dieese.

(2) Este indicador foi calculado como a razão da renda média per capita pelo custo da cesta básica per capita.

básicas) aumentou também de forma significativa nos últimos anos, comparativamente a meados do primeiro qüinqüênio. Tal fato decorre, ademais da queda do valor real da cesta, do aumento da participação de outras rendas e fontes na composição da renda familiar, seja do trabalho de outros membros (cônjuges, por exemplo), seja de auxílios, segurodesemprego, aposentadoria ou trabalho ocasional do chefe. No primeiro semestre de 1990, estas rendas equivaliam a $38 \%$ da massa de rendimentos do trabalho; no final de 1997 , este fator já havia subido para $60 \%$. No período houve até mesmo um pequeno aumento da parcela advinda de trabalho adicional. Em ambos os casos, vale lembrar que deve-se considerar o efeito aritmético da diminuição da renda do trabalho (denominador do primeiro e segundo fatores do modelo).

\section{CONCLUSÃO}

Os anos 90 foram marcados por períodos de oscilações conjunturais expressivas da renda média per capita, de sua distribuição e da proporção de indigentes, reproduzindo em pequenos ciclos experiências históricas das três últimas décadas, como analisaram Barros e Mendonça (1996). Na recessão dos primeiros anos da década de 90 a renda caiu, o perfil distributivo se agravou e certamente aumen- tou o grau de indigência (seja pelo aumento do custo da cesta básica de alimentos, seja pela queda da renda das famílias nos estratos inferiores). Com a retomada das atividades econômicas em 1993, a renda per capita média aumentou, sem que se revertesse a tendência à maior concentração de renda. O comportamento da cesta básica e da renda per capita dos $20 \%$ mais pobres sugere que a indigência deve ter diminuído em relação ao auge da crise de 1991-92. Com a implantação do Plano Real e durante mais algum tempo, com queda da inflação, maior oferta de produtos agrícolas e elevação real do salário mínimo (e por conseguinte, aposentadorias e outros benefícios), conseguiu-se combinar aumento real de renda per capita, melhoria do perfil distributivo e diminuição da indigência. A partir de 1996, contudo, a renda per capita voltou a cair e o perfil distributivo agravou-se. Ainda assim, por conta da queda real do custo da cesta básica, o grau de indigência parece ter continuado a diminuir.

Enfim, ainda que possam ser implementadas muitas outras estratégias inovadoras - mais focalizadas ou mais universalistas - para se minorar o problema da indigência e pobreza no país, como a distribuição de cestas de alimentos, as frentes de trabalho, etc., a experiência recente tem demonstrado que as iniciativas para reduzir o custo real da cesta básica (como a desoneração de impos- 
tos de alimentos básicos, incentivos à produção agrícola, oferta regulatória de produtos no mercado) e a elevação do valor real do salário mínimo (que garanta aumentos reais nos benefícios da previdência, por exemplo) são peças indispensáveis em uma política mais abrangente de superação das iniqüidades sociais no país. Ainda que o impacto destas medidas sobre a distribuição de renda possa ser pequeno, dadas as raízes históricas que estão por trás desta chaga social no Brasil, ao menos se poderá estar garantindo condições mínimas de uma sobrevivência mais digna para milhões de brasileiros.

\section{NOTAS}

E-mail dos autores: ndini@seade.gov.br / jannuzzi@seade.gov.br / mpferrei@seade.gov.br / narizono@seade.gov.br

Este trabalho é um dos produtos das atividades desenvolvidas no âmbito do projeto “Acompanhamento Conjuntural da Renda e Pobreza na RMSP", entre 1997 e 1998, e constitui-se numa síntese do que foi apresentado no IV Encontro Nacional de Estudos do Trabalho, promovido pela Abet em 1999. O projeto foi coordenado por Felícia Madeira, diretora adjunta de Análise Socioeconômica da Fundação Seade, e por Alfonso Árias, consultor do Ipea. Além dos coordenadores e dos autores deste trabalho, também participaram do referido projeto os analistas Cornélia Nogueira Porto e Maurício Soares, ambos do Dieese, Olavo Viana Costa, Sinésio Pires Ferreira, Sonia Nahas de Carvalho, Maria Alice Cutrim e Elaine Garcia Nery, da Fundação Seade. Cabe somente aos autores a responsabilidade por eventuais falhas e limitações de enfoque do presente texto.

1. Vale citar, entre outras publicações analíticas sobre as condições sociais e acesso a políticas públicas que viriam surgir neste contexto, os relatórios da Unicef, o relatório sobre a situação social do país (Nepp/Unicamp) e compilações de indicadores sociais do IBGE.

2. Naturalmente, acrescente-se a estas iniciativas o grande volume de análises de políticas públicas e de diagnósticos da realidade social realizados nas universidades e outros institutos de pesquisa, por encomenda ou não dos agentes públicos, em seus diferentes níveis.

3. A Pesquisa de Condições de Vida foi realizada pela primeira vez em 1990 na RMSP. Foi reaplicada em 1994, abrangendo, além da RMSP, um conjunto de 37 municípios do interior do Estado de São Paulo. Em 1998, ampliou-se o universo espacial para incluir 73 municípios e passou a coletar com maior detalhe informações sobre rendimentos e acesso a programas sociais. Com relação à Pesquisa de Emprego e Desemprego, nos últimos quatro anos foram aplicados, de forma complementar à pesquisa básica, questionários sobre acidentes de trabalho, experiência anterior de trabalho e qualificação profissional. Na área de habitação popular foram realizados levantamentos de campo para caracterização socioeconômica da população demandante de programas habitacionais e população residente em áreas de ocupação urbana irregular.

4. Cabe observar que entre os $5 \%$ de famílias mais pobres o peso destas rendas é um pouco menor $(93 \%)$. Naturalmente, cabe uma reavaliação destas cifras com a incorporação de novas fontes de rendimentos na PCV 98 (rendimentos financeiros, doação de terceiros, etc.) e as mudanças de composição da renda familiar observadas nos últimos quatro anos (Dini et alii, 1998).

5. Por questões de precisão estatística dos fatores do modelo analítico empregado, as estimativas de renda e de outros indicadores neste trabalho referem-se a semestres. 6. Seria possível adaptar o modelo proposto por Árias (1996) em termos de renda familiar por adulto equivalente. O esforço e os questionamentos metodológicos com relação às escalas de equivalência usadas - em geral baseadas apenas em diferenças de requerimentos energéticos por sexo e idade - não parecem justificar a empreitada, sobretudo se se objetiva garantir maior clareza na exposição de resultados para os formuladores de política social. Ainda assim, vale registrar que prosseguem os esforços de escalas de equivalência mais sofisticadas, procurando incorporar os ganhos de escala no usofruto de certos produtos ou serviços (habitação, por exemplo), como mostram os trabalhos reunidos em Ekert-Jaffé (1994).
7. Observe-se que se trata da decomposição da massa de rendimentos familiares per capita, aqui denominada de renda familiar per capita para maior fluidez na redação do texto. Tal indicador tende a fornecer estimativas diferentes da média de rendimentos familiares per capita computados para cada família, mas tem comportamento tendencialmente próximo.

8. É bem verdade, neste caso, que o perfil distributivo da renda se agravaria, outra situação indesejável em termos de bem-estar social.

9. O período de 1990-98 foi dividido, para fins analíticos, em cinco subperíodos, que demarcam ciclos de desaquecimento/recuperação da economia ou contextos político-institucionais (e político-econômicos) específicos da história nacional recente, a saber: primeiro semestre de 1990 a primeiro semestre de 1992 (recessão no Governo Collor); primeiro semestre de 1992 a primeiro semestre de 1994 (recuperação da atividade econômica no Governo Itamar); primeiro semestre de 1994 a primeiro semestre de 1995 (implantação do Plano Real); primeiro semestre de 1995 a segundo semestre de 1996 (efetivação do Plano Real) e segundo semestre de 1996 a segundo semestre de 1998 (desaquecimento induzido da economia decorrente dos desequilíbrios internos em face de um novo contexto internacional).

10. A opção por estratos relativos de renda per capita - quintis - justifica-se pelo fato de que, em estudos referidos a momentos de fortes variações conjunturais do valor real da renda, essa opção metodológica parece preservar melhor a comparabilidade longitudinal das características dos grupos sociais no período. Os quintis de renda familiar per capita foram tomados junto ao conjunto de indivíduos, não de famílias.

11. Naturalmente, na interpretação deste fator, é preciso levar em conta que sua variação depende não apenas de aumentos ou reduções da massa de outras rendas na composição da renda familiar - que afetam o numerador deste indicador mas também do efeito aritmético decorrente das alterações sofridas pela massa de renda dos trabalhos - que constitui o denominador no cômputo deste fator.

12. Indigência e pobreza referem-se aqui a situações de carência de renda para aquisição de uma cesta básica de alimentos e de uma cesta mínima de produtos e serviços, respectivamente. Neste tópico infere-se apenas sobre as tendências da indigência na RMSP nos anos 90, tarefa mais simples que a da pobreza, em função de suas definições operacionais.

13. A cesta básica de alimentos aqui empregada, calculada por Cornélia Nogueira Porto/Dieese, foi baseada no conjunto de produtos (e quantidades) incluídos na cesta Cepal (1991) para a RMSP, com utilização dos preços coletados pelo ICV-Dieese no período.

\section{REFERÊNCIAS BIBLIOGRÁFICAS}

ARANHA, V. "Migração na metrópole paulista: uma avaliação segundo a PED e PCV". X Encontro Nacional de Estudos Populacionais. Anais... Caxambu, Abep, out. 1996, p.705-724.

ÁRIAS, A. Evolução recente da renda domiciliar per capita nas 6 maiores regiões metropolitanas e seus efeitos sobre a extrema pobreza. Brasília, Ipea, 1996.

Sobre a evolução da situação social na Região Metropolitana de São Paulo na década dos 90 sob a ótica da renda familiar. Brasília, Ipea, 1998, mimeo.

BALTAR, P.E.A; DEDECCA, C.S e HENRIQUE, W. "Mercado de trabalho no Brasil". In: OLIVEIRA, C.E.B. e MATTOSO, J.E.L. (orgs.). Crise e trabalho no Brasil. São Paulo, Scritta, 1997, p.87-108.

BARROS, R.P. e MENDONÇA, R.S.P. "Determinantes da desigualdade no Brasil”. Economia brasileira em perspectiva 1996. Rio de Janeiro, Ipea, 1996, p.421-473.

BATICH, M. e MARQUES, R.M. "Aposentados e pensionistas: quantos são e como vivem”. São Paulo em Perspectiva. São Paulo, Fundação Seade, v.12, n.14, out.-dez. 1998, p.121-128.

BERCOVICH, A.; MADEIRA, F. e TORRES, H. "Descontinuidades demográficas". 20 anos no ano 2000. São Paulo, Fundação Seade, 1998, p.2-12.

BRANDÃO, S.M. e JANNUZZI, P.M. "Manifestações de renda e pobreza nos anos 90: uma análise da situação da Região Metropolitana de São Paulo". IV Encontro Nacional de Estudos do Trabalho. Anais... São Paulo, Abet, setembro de 1995, p.153-171.

CEPAL. Magnitud de la pobreza en America Latina en los años ochenta. Santiago-Chile, 1991 
CHAHAD, J.P.Z. Oferta de trabalho e estrutura ocupacional. São Paulo, Fipe, 1981.

DINI, N.P.; FERREIRA, M.P. e NERY, E.G.M. "The effect of different sources on family income". Joint Conference IASS/IAOS. Anais... México, Inegi, 1998

DINI, N.P. et alii. "Renda familiar e distribuição de renda na RMSP nos anos 90: evolução conjuntural e seus determinantes". IV Encontro Nacional de Estudos do Trabalho. Anais... Belo Horizonte, Abet, 1999

EKERT-JAFFÉ, O. Standards of living and families: observation and analysis. Paris, John Libbey Eurotext, 1994.

ELIZAGA, J. Dinamica y economia de la población. Santiago, Celade, 1979.

FAROOQ, G.M. Population and employment in developing countries. Geneva, ILO, 1985.

FERREIRA, S.P. e AQUILINI, G.H. "Mudanças estruturais e comportamento do mercado de trabalho no Estado de São Paulo nos anos 90". São Paulo em Perspectiva. São Paulo, Fundação Seade, v.13, n.1, jan.-mar. 1999.
FUNDAÇÃO SEADE. Pesquisa de condições de vida: renda. São Paulo, 1992. O novo retrato de São Paulo. São Paulo, 1993.

Projeto de acompanhamento conjuntural da renda e pobreza na RMSP: tabulações e anexos metodológicos. São Paulo, 1999.

JANNUZZI, P.M. "Renda e estrutura de despesas familiares em São Paulo". In: PATARRA, N. et alii. Migração, emprego e condições de vida. Campinas, IE/Unicamp, 1997, p.319-407.

MAGALHÃES, M.A.E. "Questão social e análise econômica no Brasil: 1960/ 1980". Planejamento e Políticas Públicas, n.9, 1993, p.169-200.

MATTOSO, J.E.L. e BALTAR, P.E.A. "Transformações estruturais e emprego nos anos 90". Cadernos do Cesit. Campinas, n.21, 1996.

NEPP. Estratégias para combater a pobreza no Brasil: programas, instituições e recursos. Campinas, Unicamp, 1994 (Relatório final).

PNUD. Economia popular: uma via para el desarrollo sin pobreza en America Latina. Bogotá, 1991.

ROCHA, S. "Renda e pobreza: os impactos do Plano Real". Revista Brasileira de Estudos Populacionais. Campinas, v.13, n.2, jul.-dez. 1996. 